\title{
Safety of bronchodilators and corticosteroids for asthma during pregnancy: what we know and what we need to do better
}

REVIEW

\section{Thorbjørn Lomholt \\ Gregersen \\ Charlotte Suppli Ulrik}

Department of Pulmonary Medicine, Hvidovre Hospital and University of Copenhagen, Hvidovre, Denmark
Correspondence: Charlotte Suppli Ulrik Department of Pulmonary Medicine 253, Hvidovre Hospital, Kettegård Alle 30, DK-2650 Hvidovre, Denmark

Email csulrik@dadlnet.dk
This article was published in the following Dove Press journal:

Journal of Asthma and Allergy

14 November 2013

Number of times this article has been viewed

Abstract: Asthma is a common medical condition complicating pregnancy with potentially serious effects on pregnancy outcome. The aim of this review is to provide an update on efficacy and safety of asthma medications, primarily bronchodilators and corticosteroids, used during pregnancy with focus on pregnancy outcome, and, furthermore, to discuss limitations of available studies and point to possible improvements in future studies. A planned series of systematic searches was conducted using the PubMed database. Use of short-acting $\beta_{2}$-agonists has generally been established as safe, and the few studies stating otherwise appear to have, perhaps critical, methodological limitations. The safety of long-acting $\beta_{2}$-agonists remains to be further investigated, and the few available studies have methodological limitations and, therefore, provide no definite answers, although a very recent study supports the safety of add-on long-acting $\beta_{2}$-agonists to inhaled corticosteroids. Inhaled corticosteroids are generally found to be safe, although further research is needed to investigate both the efficacy and safety of high dose therapy with inhaled corticosteroids. Studies have reported associations between the use of systemic corticosteroids and adverse perinatal outcomes, such as preterm birth, low birth weight, and pre-eclampsia. This must, however, be weighed against the potential serious impact of severe, uncontrolled asthma itself on pregnancy outcome. The main obstacle to a valid interpretation of several of the available studies is the inadequate stratification for asthma severity and control. Overall, asthma in itself and not just poor asthma control poses a greater risk to pregnancy outcomes than asthma medication. Nonetheless, more studies focusing on disentangling the effects of asthma alone and asthma medications are needed. Increased use of stratified risk assessments, taking the concept of asthma severity into greater consideration, is much warranted in future studies.

Keywords: asthma, pregnancy, perinatal outcomes, asthma management, bronchodilators, inhaled corticosteroids, systemic corticosteroids

\section{Introduction}

Asthma is common among pregnant women with reported prevalence rates of up to $12 \%$, although with wide variation. ${ }^{1,2}$ Asthma, therefore, represents one of the most common medical conditions with potentially serious effects on pregnancy outcomes. ${ }^{3}$ However, ethical considerations have, for obvious reasons, limited the types of studies that have been possible to conduct. Double-blind, placebo-controlled studies are, in general, unethical in pregnant women, and this makes it difficult to control variables and isolate specific therapeutic effects. ${ }^{4}$ This calls for creative thinking in the planning of research in this area, instead of using more traditional and rigid study designs.

Management of asthma during pregnancy is not without difficulties, as both the potential detrimental effects of the disease and the possible adverse effects of the treatment on both the patient and the developing fetus must be taken into consideration. ${ }^{1,2}$ This only adds 
to the importance of health professionals being able to make weighted decisions based on sufficient knowledge of the efficacy and safety of the available treatment options for asthma, as well as of the possible consequences of inadequate treatment, which may potentially cause severe episodes of uncontrolled asthma.

The primary aim of this review is to provide an update on available evidence of the efficacy and safety of asthma medications, primarily bronchodilators and corticosteroids, used during pregnancy in relation to pregnancy outcome.

\section{Methods}

A planned series of systematic searches was conducted by both authors (last updated September 2013) using the PubMed database. The intention was to capture all results relevant to asthma and pregnancy and, afterwards, to filter out the articles falling outside the scope of the present review. The medical subject heading $(\mathrm{MeSH})$ terms asthma, asthma-like symptoms, asthma severity, airway hyperresponsiveness, airway inflammation, anti-asthma medication, asthma control, asthma management, asthma medication, bronchodilators, $\beta_{2}$-agonists, long-acting bronchodilators, short-acting bronchodilators, inhaled corticosteroids, asthma controller medication, systemic corticosteroids, and oral corticosteroids were searched in combination with the terms birth weight, congenital abnormalities, birth defects, fetal weight, intra-uterine growth, premature birth, preterm birth, pregnant, pregnancy, gestational age, prematurity, congenital malformations, fetal growth, and perinatal outcome.
A total of 138 potentially relevant articles were identified, and all of these papers were evaluated for possible inclusion in this review. All studies specifically reporting observations related to the effect of asthma medications on pregnancy outcome were reviewed, as well as papers reporting non-significant observations. Articles were included in the present review provided they fulfilled the following criteria: 1) original research; 2) addressing, at least to some extent, the distinction between effects of asthma medication and effects of asthma; 3) objective assessment, including, for example, the number and type of prescribed therapy, of asthma severity; and 4) published since 1980. Non-English papers were excluded. This review was performed in accordance with the PRISMA (Preferres Reporting Items for Systematic reviews and Meta-Analysis)-guidelines, but due to the relatively limited number of studies, and in part due to the diversity in study design, a formal meta-analysis was not performed.

\section{Results}

A total of 38 papers fulfilled the inclusion criteria and were, therefore, included in the present review (Figure 1).

\section{Safety of short-acting $\beta_{2}$-agonists}

The use of short-acting $\beta_{2}$-agonists for immediate relief of asthma symptoms during pregnancy is generally regarded as being safe. ${ }^{3-5}$

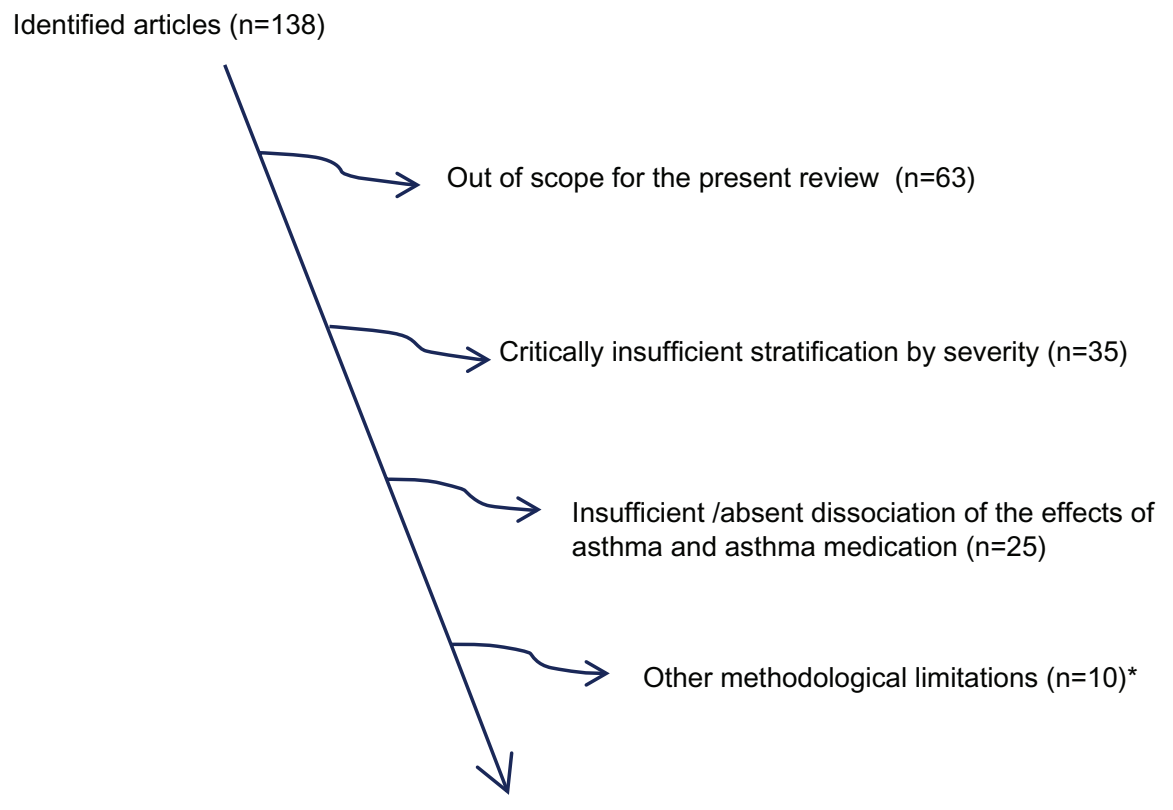

Articles included in the present review $(n=38)$

Figure I Identification and inclusions process.

Note: *Case reports, etc. 
In 2005, Bakhireva et al reported from a case-control study comprising 103 cases and 3,030 matched controls that the use of inhaled short-acting $\beta_{2}$-agonists during pregnancy is not associated with an increased risk of low birth weight; odds ratio (OR) 0.57 (95\% confidence interval [CI] $0.16-2.12) .{ }^{6}$ Severity of asthma was graded according to the level of asthma therapy, and asthma control was assessed on the basis of symptoms reported in regular telephone interviews with the enrolled pregnant women with asthma. ${ }^{6}$

In a Canadian cohort study from 2011, Eltonsy et $\mathrm{al}^{7}$ investigated the possible association between exposure to short-acting $\beta_{2}$-agonists in the first trimester of pregnancy and the risk for congenital malformations among women with asthma. The patients were recruited from individuals covered by a public drug insurance plan. Severity and control of asthma before pregnancy were assessed according to national guidelines, and during the first trimester of pregnancy based on administered daily dose of inhaled corticosteroid (if any), use of other asthma medication, unscheduled health care visits, and use of oral corticosteroids. A total of 13,117 pregnancies were included in the study and 1,242 infants with "any" and 762 infants with "major" malformations, respectively, were identified. The authors observed no association between first trimester use of shortacting $\beta_{2}$-agonist and congenital malformations; the adjusted ORs being 1.04 (95\% CI: $0.92-1.17)$ and 0.93 (95\% CI: $0.80-1.08)$, respectively. ${ }^{7}$

In line with this, a cohort study by Schatz et $\mathrm{a}^{8}$ from 2004, comprising 1,828 pregnant women, recruited from a multicenter surveillance network, who used $\beta_{2}$-agonists found no association with adverse perinatal outcomes defined as low birth weight, small gestational age, or major congenital malformations. Importantly, this study sought to stratify informants according to several parameters, including asthma severity, which was classified as mild, moderate, or severe, based on a combination of level of lung function, symptom frequency, use of asthma medication, and unscheduled health care visits. ${ }^{8}$

However, in contrast to the abovementioned studies, some studies have reported conflicting results. From a populationbased case-control study, where disease severity was assessed only on the basis of medication use, published in 2009, Lin et al reported a small increase in risk of congenital heart defects when considering only unspecified bronchodilator use with an OR of 2.20 (95\% CI: 1.05-4.61) in a sample of 22 cases and 22 controls. ${ }^{9}$

In a further case-control study including 381 infants born with gastroschisis and 4,121 infants born without malformations Lin et a ${ }^{10}$ reported an association between the presence of gastroschisis and use of bronchodilators during the period of conception (1-month pre-pregnancy until the end of first trimester). A total of 113 women used a short-acting $\beta_{2}$-agonist, a long-acting $\beta_{2}$-agonist or both. Seventy-one percent of the cases and $89 \%$ of the controls used the shortacting $\beta_{2}$-agonist albuterol (salbutamol). The reported OR of 2.06 (95\% CI: 1.19-3.59) reflects the combined risk of using inhaled $\beta_{2}$-agonists. Of notice in relation to this study is that asthma severity could only be evaluated on the basis of used asthma medication, and by that information on asthma control was not reported and, therefore, the adverse outcomes may also have been the result of poor asthma control, including insufficient use of controller medication. ${ }^{10}$

Finally, a 2011 case-control study by Munsie et al ${ }^{11}$ comprising, by way of self-reporting in standardized interviews, 2,711 infants born with oro-facial cleft and 6,482 infants born without malformations, also reported an association between bronchodilator use in the period around conception and the congenital malformation. The total sample of bronchodilator users comprised 247; ie, 89 cases and 158 controls, respectively. The analysis revealed a statistically significant association between bronchodilator use and cleft lip (adjusted OR 1.77 [95\% CI: 1.08-2.88]), whereas the association was non-significant for cleft palate (adjusted OR 1.53 [95\% CI: 0.99-2.37]). The majority (88.7\%) of the women reported using albuterol (salbutamol), and the use of this short-acting $\beta_{2}$-agonist alone was shown to be significantly associated with cleft lip (adjusted OR 1.79 [95\% CI: 1.07-2.99] and also cleft palate (adjusted OR 1.65 [95\% CI: 1.06-2.58]). A total of 18 and 25 cases, respectively, and 101 controls were included in analysis addressing potential risk of albuterol (salbutamol). Similar to the abovementioned studies, information on asthma control was not reported, and disease severity could only by assessed on the basis of types of asthma medications used. ${ }^{11}$

Based on the available evidence, the use of short-acting $\beta_{2}$-agonists during pregnancy for relief of acute asthma symptoms appears to be safe.

\section{Safety of long-acting $\beta_{2}$-agonists}

The safety of long-acting $\beta_{2}$-agonists used as add-on to inhaled corticosteroids in pregnant women remains to be firmly established, ${ }^{2,4,12}$ although several previous studies found no statistically significant association with congenital malformations. ${ }^{5,7}$

The abovementioned 2011 cohort study by Eltonsy et $\mathrm{al}^{7}$ suggested that use of long-acting $\beta_{2}$-agonists may carry an 
increased risk of congenital malformations, although the findings were not statistically significant with an adjusted OR 1.37 (95\% CI: 0.92-2.17) for any malformations and OR 1.31 (95\% CI: 0.74-2.31) for major malformations.

Furthermore, a small prospective study by Clifton et $\mathrm{al}^{13}$ showed that while use of the inhaled glucocorticoid fluticasone propionate alone was associated with normal neonatal birth size, fixed combination therapy with fluticasone propionate and the long-acting $\beta_{2}$-agonist salmeterol was associated with reduced neonatal birth weight centiles (mean 34.8; SEM [standard error of the mean] 9.3; $P=0.011$ ). However, the total population of asthmatic pregnancies was only $n=41$ and only nine women were treated with the fixed fluticasone/salmeterol combination; and, furthermore, based on the available information, bias by indication appears to be a possibility, as asthma severity assessment could only be based on prescribed asthma medication.

In a very recent study, Cossette et $\mathrm{al}^{14}$ studied the impact of maternal use of asthma-controller medication on risk for low birth weight, preterm birth, and small for gestational age. The severity of asthma in the year before conception was measured with a validated algorithm that categorizes asthma into mild, moderate, or severe. Furthermore, asthma control during pregnancy was assessed by weekly use of rescue bronchodilators, use of oral corticosteroids and whether the women had a hospital admission or an emergency department visit for asthma. The cohort comprised 6,199 women contributing 7,376 pregnancies, of whom $8.8 \%$ were exposed to long-acting $\beta_{2}$-agonists; women treated with long-acting $\beta_{2}$-agonists without concomitant inhaled corticosteroids were excluded from the study. The authors observed no association between use of long-acting $\beta_{2}$-agonists and the adverse perinatal outcomes of interest.

The safety of treatment with inhaled long-acting $\beta_{2}$-agonists during pregnancy needs to be further investigated. However, the available studies suggests that long-acting $\beta_{2}$-agonists used as add-on to inhaled corticosteroids for pregnant women with more severe asthma are safe, as bias by indication might explain the previously reported adverse effects on pregnancy outcome.

\section{Efficacy and safety of inhaled corticosteroids}

Clinical experience and several studies suggest that the use of inhaled corticosteroids (ICS) for asthma control during pregnancy is generally safe and that the risks associated with non-adherence to prescribed ICS pose a much greater threat to perinatal outcome. . $^{2,5,15,16}$
As mentioned above, the number of available controlled trials addressing efficacy and safety of medication used for asthma during pregnancy is extremely limited. However, in a randomized controlled trial, Dombrowski et a ${ }^{17}$ compared the efficacy of inhaled beclomethasone dipropionate to oral theophylline for the prevention of asthma exacerbations requiring medical intervention in pregnant women with moderate asthma. Asthma severity was assessed on the basis of symptoms and treatment; patients regarded as having severe or unstable asthma were excluded from the study. The study revealed no significant difference in the proportion of asthma exacerbations between the two treatment groups, but the beclomethasone treated group was less likely to discontinue treatment due to side effects and have forced expiratory volume $\left(\mathrm{FEV}_{1}\right)$ below $80 \%$ predicted at study visits. No significant differences were observed between the groups with regard to treatment failure or compliance; and no significant differences were observed in maternal or perinatal outcomes. The authors, therefore, concluded that the efficacy of ICS was good and, furthermore, that their findings were in favor of ICS for moderate asthma during pregnancy. A total of 4,975 women were assessed for eligibility, of whom 398 fulfilled the inclusion criteria and were randomized, 194 and 191, respectively, completed the study and were included in the analysis. In accordance with the study design, observations regarding the effects of asthma versus effects of asthma medication were not reported.

However, in spite of the reassuring findings regarding the use of low to medium dose ICS, several studies have raised safety concerns with regard to the use of high dose ICS during pregnancy. In a large 2007 cohort study comprising data from 4,561 pregnancies complicated by asthma, Blais et $\mathrm{al}^{18}$ observed a non-significant adjusted OR of $1.67(95 \%$ CI: 0.56-5.03) for major congenital malformations after use of high dose ICS during the first trimester of pregnancy (defined as $\geq 1,000 \mu \mathrm{g} /$ day beclomethasone [BDP] equivalent dose). A malformation was defined as major if life threatening or causing major cosmetic defects, and at least one hospitalization during the first year of life. The analysis was adjusted for confounding factors such as use of other teratogenic medications, smoking, drinking, and other medical conditions. ${ }^{14}$

Another cohort study, also by Blais et al, ${ }^{19}$ comprising 13,280 pregnancies complicated by asthma, revealed that asthmatic women on high dose ICS (defined as above) had a significantly increased risk of giving birth to a child with a malformation compared to asthmatic women treated with a lower dose of ICS, the adjusted odds ratio being 1.63 (95\% CI: $1.02-2.60) .{ }^{19}$ 
Finally, a previously published cohort study comprising 13,004 pregnancies by Breton et $\mathrm{al}^{20}$ showed a non-significant increase in risk of perinatal mortality (adjusted OR 1.52 [95\% CI: $0.62-3.76]$ ) in women treated with $\geq 250 \mu \mathrm{g} /$ day BDP equivalent dose of ICS during pregnancy; probably at least partly reflecting that the study had low power (24\%) to detect a difference in the outcome of interest. Data on socioeconomic status, concomitant medical conditions, and use of other asthma medications were included in the analysis as confounding factors.

In the abovementioned study by Cossette et al ${ }^{14}$ the possible association was also studied between exposure to inhaled corticosteroids during pregnancy and adverse perinatal outcome; ie, low birth weight, preterm birth, and small for gestational age. Exposure to ICS during pregnancy was documented for $56.9 \%$ of the 7,376 pregnancies included in the analysis. No association was observed between low-dose ICS and the outcomes of interest, whereas a non-significant increasing trend in the prevalence of all three outcomes was observed with increasing doses of ICS $>200 \mu \mathrm{g}$ BDP equivalent per day (ie, $>125 \mu \mathrm{g} /$ day of fluticasone).

Low to middle dose inhaled corticosteroid as controller therapy for asthma during pregnancy is generally safe, whereas the safety, and similar to observations in nonpregnant patients with asthma probably also the efficacy, of high-dose inhaled corticosteroid during pregnancy should be further investigated.

\section{Safety of systemic corticosteroid use in pregnancy}

For pregnant patients with asthma, just like in non-pregnant patients, systemic corticosteroids are used only for treatment of acute exacerbations of asthma or as the last resort in cases with difficult to control severe asthma, ${ }^{12}$ and systemic corticosteroids are, therefore, almost always prescribed in combination with ICS with or without long-acting $\beta_{2}$-agonists. ${ }^{21}$

Several studies have pointed to the adverse effects of systemic corticosteroid therapy on perinatal outcome, but these findings should, however, be balanced against the importance of controlling severe and/or exacerbated asthma. ${ }^{6,8,22-25}$

Schatz et $\mathrm{al}^{22}$ assessed the safety of $\beta_{2}$-agonists, theophylline, sodium cromoglycate, corticosteroids, anti-histamines, and decongestants in a prospective cohort study comprising 824 asthmatic and 678 non-asthmatic pregnant women. Only prescription of oral corticosteroids was found to be associated with a significant increase in risk of pre-eclampsia (OR 2.0 [95\% CI: 1.11-3.61]) after adjusting for the effects of several confounding factors, but not stratified for asthma severity. ${ }^{21} \mathrm{In}$ keeping with this, Martel et $\mathrm{al}^{23}$ have previously from a nested case-control study reported an increased risk for pregnancyinduced hypertension and pre-eclampsia in women treated with oral corticosteroids during pregnancy.

In contrast to this, Bracken et $\mathrm{al}^{24}$ performed a prospective cohort study of 873 pregnant women with a history of asthma and 1,333 pregnant women with no history of asthma, where they sought to classify patients according to asthma symptoms (frequency), asthma medication use, and asthma severity (intermittent/mild, persistent/moderate, persistent/severe, persistent). Severity and frequency of symptoms were not significantly associated with an increased risk of preterm delivery. However, the use of oral corticosteroids was found to be associated with an increased risk of preterm delivery (OR 3.37 [95\% CI: 1.66-6.86]); the mean reduction in gestational age being 2.22 weeks. $^{24}$

In the abovementioned study by Schatz et al, ${ }^{8}$ the use of oral corticosteroids was found to be significantly associated with an increased risk of preterm birth (OR 1.54 [95\% CI: 1.02-2.33]) and, furthermore, also an increased risk of birth weight $<2,500 \mathrm{~g}$ with an OR of 1.80 (95\% CI: 1.13-2.88). Importantly, this study tried to adjust for demographic parameters and asthma severity by using a classification into mild, moderate, and severe cases. ${ }^{8}$

Furthermore, the previously mentioned study by Bakhireva et $\mathrm{al}^{6}$ showed that use of systemic corticosteroids was associated with a birth weight on average $200 \mathrm{~g}$ lower than in the control group without asthma $(P<0.01){ }^{6}$

In 2012, Murphy et $\mathrm{al}^{25}$ published an analysis of a double-blind randomized controlled trial of antenatal corticosteroid use for fetal lung development in women in perceived risk of preterm birth revealing findings of interest for the current review, although as a non-asthma study it did not fulfill our inclusion criteria. A total of 1,858 women giving birth to 2,304 children were included in the analysis. Compared to placebo, infants exposed to corticosteroids were born earlier ( -0.43 weeks, $95 \%$ CI: -0.10 to -0.75 ; $P=0.01)$ and infants exposed to multiple courses of antenatal corticosteroids had decreased birth weight $(-33.50 \mathrm{~g}$, 95\% CI: -66.27 to $-0.73 ; P<0.05)$, length $(-0.34 \mathrm{~cm}$, 95\% CI: -0.62 to $-0.06 ; P=0.02)$, and head circumference $(-0.30 \mathrm{~cm}, 95 \%$ CI: -0.46 to $-0.14 ; P<0.001)$. A doseresponse relation was also found, as an increase in exposure produced a trend towards an increase in these adverse outcomes. Importantly, the study controlled for gestational age as a confounding factor. ${ }^{25}$

Studies published so far addressing the possible association between treatment with systemic corticosteroids 
and pregnancy outcome have reported associations between systemic steroid exposure and adverse pregnancy outcomes, including low birth weight, pre-term birth, and pre-eclampsia.

\section{The effects of asthma alone versus the effects of asthma medication}

Many studies have reported associations between asthma and asthma medications, and on the other hand adverse perinatal outcomes, but most often the attempts and/or ability to separate the two causalities in the available studies have been at best vague. However, a few recent studies have actively sought to or, perhaps, by chance succeeded in making this distinction.

In a 2008 study which sought to separate the adverse effect of systemic corticosteroids from the effect of asthma exacerbations, Blais and Forget ${ }^{26}$ performed an analysis excluding pregnant women with asthma on maintenance treatment with systemic corticosteroids in the year before conception; asthma severity in women eligible for inclusion in the study were assessed on the basis of prescribed asthma medication and unscheduled health care contacts for asthma in the pre-pregnancy period. From this group of women $(n=4,344)$ they reported that those who experienced an exacerbation, defined as a filled prescription of oral corticosteroids, an emergency department visit for asthma, or a hospitalization for asthma, were twice as likely to give birth to a child with a major malformation than those who did not experience an exacerbation of asthma during pregnancy. ${ }^{26}$

In keeping with this, Lao and Huengsburg ${ }^{27}$ found, in a retrospective study of 87 singleton pregnancies compared to a group of controls, an increased incidence of low birth weight in children born by mothers with asthma, but the incidence was primarily increased in pregnancies with asthma that had not required the use of bronchodilator therapy, or at least in which this possibility of reliever therapy had not been used. In short, children born by mothers with mild but untreated asthma had lower birth weight than children born to women with more severe but treated asthma. ${ }^{27}$ It may be speculated that the women without prescriptions for asthma medication did in fact have asthma which justified medical treatment.

Also, Olesen et $\mathrm{al}^{28}$ observed in a population-based prescription study comprising 303 pregnant women with asthma that infants born to women who received prescriptions for asthma medications during pregnancy had birth weights and birth lengths within the expected limits. However, concurrently they observed that women who reduced the intensity of their asthma treatment during pregnancy gave birth to low birth weight ( $-116.9 \mathrm{~g} ; 95 \% \mathrm{CI}$ : -217.8 to -15.9 , compared to increase in therapy, $-155.7 \mathrm{~g}$; $95 \% \mathrm{CI}:-314.5$ to 3.1$)$ and short birth length children (compared to reference, $-0.8 \mathrm{~cm} ; 95 \%$ CI: -1.2 to -0.3 , compared to increase in therapy, $-0.8 \mathrm{~cm}$; 95\% CI: -1.6 to -0.1$){ }^{28}$

Based on the available studies, it seems difficult to draw valid conclusions with regard to effect of asthma per se and asthma medication on pregnancy, but overall it appears that the impact of asthma, especially poorly controlled asthma, on risk for adverse pregnancy outcome is more pronounced than the effect of asthma medication.

\section{Discussion}

Use of short-acting $\beta_{2}$-agonists appears to be safe, but the safety of long-acting $\beta_{2}$-agonists remains to be completely established, although a very recent study is reassuring. ${ }^{14}$ ICS are generally safe, but more research is needed to investigate the safety of high dose therapy (defined as $>1,000 \mu \mathrm{g}$ of beclomethasone equivalent daily). And, finally, studies have reported associations between the use of systemic corticosteroids and adverse perinatal outcomes, such as preterm birth, low birth weight, and pre-eclampsia.

Many of the currently unsolved problems related to asthma in pregnancy, including the ones presented in the present review, regard the obstacle of disentangling the effect of asthma alone from the effect of asthma medications. ${ }^{4,24}$ Studies that report a lack of ability to distinguish between these causalities include results ranging from increased prevalence of Cesarean section, ${ }^{4}$ pre-eclampsia, infant hypoglycemia, ${ }^{29,30}$ gestational diabetes, post-term delivery, ${ }^{29}$ pre-term delivery, ${ }^{8}$ and malformations. ${ }^{9,31-33}$

While the study by Olesen et $\mathrm{al}^{28}$ lends more support to the safety of at least some asthma medications, it indicates that asthma which is subjectively perceived as not being severe enough to demand continued treatment may still be severe enough to cause adverse perinatal outcomes. Another possibility is that the women who decided to decrease or even discontinue treatment did so out of fear for the potential harm of asthma medications, perhaps even ignoring asthma symptoms. In support of this statement, several studies have shown that pregnant patients with asthma often feel poorly supported by health care providers in managing asthma during pregnancy in spite of personal concerns about adverse outcomes. ${ }^{34}$ Perhaps as a consequence, many report nonadherence to prescribed anti-asthmatic drugs, insufficient knowledge of both the effects and risk of the medication, ${ }^{35}$ over-estimation of teratogenic effects, ${ }^{36}$ and hesitation to use medication even when symptoms worsen. ${ }^{37}$ These results 
suggest that there is a widespread need for and a great potential in more affirmative action and education targeted at pregnant asthmatics. This may hitherto, at least partly and most probably with varying degrees according to the specific health care system, have been inhibited by a lack of confidence and/or knowledge among health care professionals. ${ }^{38}$ As an example, in $2011 \mathrm{McC}$ Callister et al found that a population of pregnant women visiting the emergency department with acute exacerbations of asthma were less likely to receive appropriate treatment with systemic corticosteroids. ${ }^{39}$ This is in spite of the many studies that have confirmed the crucial importance of efficient asthma control in pregnancy.

The not fully answered questions especially regarding long-acting $\beta_{2}$-agonists and high doses of inhaled corticosteroids warrant further research, but it must again be noted that these types of therapy are all directed at controlling moderate to severe asthma which in itself poses a big threat to perinatal outcome. It has already been found that spirometry provides a better prediction of perinatal outcome than a measurement of asthma symptoms alone ${ }^{40}$ and more research linking objective measurements of asthma severity to perinatal outcome is needed so as to cast light on the effect of uncontrolled asthma and asthma exacerbations, potentially leading to maternal hypoxia, on the fetus.

Short-acting $\beta_{2}$-agonists have generally been established as safe, and studies producing conflicting results have lacked strength either due to small sample sizes or lack of adjustment for asthma severity. This does not rule out that specific risks exist, and further research is warranted, but in light of stratified risk assessments based on larger samples in consideration of asthma severity and use of other asthma medications. The studies reporting adverse results described here failed to do so.

The safety of long-acting $\beta_{2}$-agonists as add-on controller therapy for patients with moderate to severe asthma has been much debated, also in non-pregnant patients with asthma. ${ }^{41}$ Although several studies in non-pregnant patients with asthma have documented the beneficial effect of add-on long-acting $\beta_{2}$-agonists to ICS on asthma control, ${ }^{42}$ there is a scarcity of research focusing on safety aspects of the use of long-acting $\beta_{2}$-agonists, and the available recent studies have produced results that raise some concerns that should be addressed. ${ }^{41,43}$ These drugs are usually prescribed for women with more severe asthma, and the studies described here have also utilized data from such context; where asthma severity again may act as an important confounder and the use of long-acting $\beta_{2}$-agonists may in itself merely be an indicator of more severe asthma.
Although some studies have produced results that give some reason for concern regarding the use of high doses of ICS and possible teratogenic effects, some weaknesses and general considerations also apply to these studies, as best described by Blais et al, ${ }^{19}$ as they stated that high doses of ICS are known to have systemic effects, and systemic corticosteroids are known to have adverse effects in pregnancy. ${ }^{19}$ However, women using high doses of ICS are characterized by more severe and more poorly controlled asthma with greater risk of acute exacerbations and poorly controlled asthma and exacerbations in asthma are known as the overall greatest dangers to perinatal outcome. ${ }^{19}$

As for other types of medication, only analyses outside the context of multi-drug therapy will reveal the objective effects of systemic corticosteroids as an isolated treatment, as it is not yet clear if the risk is the medication, the combination of multiple drugs, or the severity of the disease. Another suggestion which has been made, ${ }^{6}$ and which needs further research, is the possibility that women who make a claim for systemic corticosteroids share a hidden pathogenetic confounder which affects perinatal outcome. Confounding by severity is stronger in studies of systemic corticosteroids than in the studies of other types of asthma medications, which makes this type of direct study particularly challenging. Some interesting results have been produced by addressing the problem less directly and looking at exacerbations in women without a prescription for systemic corticosteroids. ${ }^{2,3}$ However, this strategy may not be applied easily to study the effects of persistent severe asthma as women in this category are more likely to make use of the drug.

Studies that have succeeded in separating the effects of asthma from the effects of asthma medication all point to the possible detrimental effects on perinatal outcome of asthma alone; including even mild manifestations of the disease. ${ }^{28}$ There is, however, a lack of studies addressing this question, and also a great need for developing intelligent study designs for that purpose. The study of effects of any medications in pregnant women entails some ethical considerations that require inventing unorthodox methodological approaches to the subject, but this has so far been very much neglected in the study of asthma medications.

Assessing the effect and safety of multi-drug asthma therapies is challenging because most treatment of moderate and severe asthma is based on this type of therapy. ${ }^{21}$ Thus, the group of patients receiving multi-drug therapy is a group already greatly affected by the potential severity of asthma alone. It remains, nonetheless, to be firmly established if there 
are possible negative consequences for perinatal outcome from this type of therapy in pregnant women. The indication of a possible association between fluticasone/salmeterol combination therapy and reduced birth weight ${ }^{13}$ seems to have been much of a chance finding, and in itself this calls for more systematic research.

In summary, the primary motivations for more and improved research in asthma generally and asthma in pregnancy specifically must be both the high prevalence and the potential severity of the condition. Only one manifestation of asthma in a pregnant woman may potentially adversely affect the whole life of the yet unborn child.

\section{Disclosure}

The authors report no conflicts of interest in this work.

\section{References}

1. Tan KS, Thomson NC. Asthma in pregnancy. Am J Med. 2000;109(9): 727-733.

2. Murphy VE, Gibson PG. Asthma in pregnancy. Clin Chest Med. 2011;32(1):93-110, ix.

3. Rocklin RE. Asthma, asthma medications and their effects on maternal/fetal outcomes during pregnancy. Reprod Toxicol. 2011;32(2): 189-197.

4. Guy ES, Kirumaki A, Hanania NA. Acute asthma in pregnancy. Crit Care Clin. 2004;20(4):731-745, x.

5. Vasilakis-Scaramozza C, Aschengrau A, Cabral HJ, Jick SS. Asthma drugs and the risk of congenital anomalies. Pharmacotherapy. 2013;33(4):363-368.

6. Bakhireva LN, Jones KL, Schatz M, Johnson D, Chambers CD; Organization Of Teratology Information Services Research Group. Asthma medication use in pregnancy and fetal growth. J Allergy Clin Immunol. 2005;116(3):503-509.

7. Eltonsy S, Forget A, Blais L. Beta2-agonists use during pregnancy and the risk of congenital malformations. Birth Defects Res A Clin Mol Teratol. 2011;91(11):937-947.

8. Schatz M, Dombrowski MP, Wise R, et al; Maternal-Fetal Medicine Units Network, The National Institute of Child Health and Development; National Heart, Lung and Blood Institute. The relationship of asthma medication use to perinatal outcomes. J Allergy Clin Immunol. 2004;113(6):1040-1045.

9. Lin S, Herdt-Losavio M, Gensburg L, Marshall E, Druschel C. Maternal asthma, asthma medication use, and the risk of congenital heart defects. Birth Defects Res A Clin Mol Teratol. 2009;85(2):161-168.

10. Lin S, Munsie JP, Herdt-Losavio ML, et al; National Birth Defects Prevention Study. Maternal asthma medication use and the risk of gastroschisis. Am J Epidemiol. 2008;168(1):73-79.

11. Munsie JW, Lin S, Browne ML, et al; National Birth Defects Prevention Study. Maternal bronchodilator use and the risk of orofacial clefts. Hum Reprod. 2011;26(11):3147-3154.

12. Bakhireva LN, Schatz M, Chambers CD. Effect of maternal asthma and gestational asthma therapy on fetal growth. J Asthma. 2007;44(2): 71-76.

13. Clifton VL, Rennie N, Murphy VE. Effect of inhaled glucocorticoid treatment on placental 11 beta-hydroxysteroid dehydrogenase type 2 activity and neonatal birthweight in pregnancies complicated by asthma. Aust N Z J Obstet Gynaecol. 2006;46(2):136-140.

14. Cossette B, Forget A, Beauchesne MF, et al. Impact of maternal use of asthma-controller therapy on perinatal outcomes. Thorax. 2013;68(8): 724-730.
15. Rahimi R, Nikfar S, Abdollahi M. Meta-analysis finds use of inhaled corticosteroids during pregnancy safe: a systematic meta-analysis review. Hum Exp Toxicol. 2006;25(8):447-452.

16. Lemiere $\mathrm{C}, \mathrm{Blais} \mathrm{L}$. Are inhaled corticosteroids taken during pregnancy harmless? J Allergy Clin Immunol. 2005;116(3):501-502.

17. Dombrowski MP, Schatz M, Wise R, et al; National Institute of Child Health and Human Development Maternal-Fetal Medicine Units Network; National Heart, Lung, and Blood Institute. Randomized trial of inhaled beclomethasone dipropionate versus theophylline for moderate asthma during pregnancy. Am J Obstet Gynecol. 2004;190(3): 737-744.

18. Blais L, Beauchesne MF, Rey E, Malo JL, Forget A. Use of inhaled corticosteroids during the first trimester of pregnancy and the risk of congenital malformations among women with asthma. Thorax. 2007;62(4):320-328.

19. Blais L, Beauchesne MF, Lemière C, Elftouh N. High doses of inhaled corticosteroids during the first trimester of pregnancy and congenital malformations. J Allergy Clin Immunol. 2009;124(6):1229-1234. e4.

20. Breton MC, Beauchesne MF, Lemière C, Rey É, Forget A, Blais L. Risk of perinatal mortality associated with inhaled corticosteroid use for the treatment of asthma during pregnancy. J Allergy Clin Immunol. 2010;126(4):772-777. e2.

21. Tamási L, Horváth I, Bohács A, Müller V, Losonczy G, Schatz M. Asthma in pregnancy - immunological changes and clinical management. Respir Med. 2011;105(2):159-164.

22. Schatz M, Zeiger RS, Harden K, Hoffman CC, Chilingar L, Petitti D. The safety of asthma and allergy medications during pregnancy. J Allergy Clin Immunol. 1997;100(3):301-306.

23. Martel MJ, Rey E, Beauchesne MF, et al. Use of inhaled corticosteroids during pregnancy and risk of pregnancy induced hypertension: nested case-control study. BMJ. 2005;330(7485):230.

24. Bracken MB, Triche EW, Belanger K, Saftlas A, Beckett WS, Leaderer BP. Asthma symptoms, severity, and drug therapy: a prospective study of effects on 2205 pregnancies. Obstet Gynecol. 2003;102(4): 739-752.

25. Murphy KE, Willan AR, Hannah ME, et al; Multiple Courses of Antenatal Corticosteroids for Preterm Birth Study Collaborative Group. Effect of antenatal corticosteroids on fetal growth and gestational age at birth. Obstet Gynecol. 2012;119(5):917-923.

26. Blais L, Forget A. Asthma exacerbations during the first trimester of pregnancy and the risk of congenital malformations among asthmatic women. J Allergy Clin Immunol. 2008;121(6):1379-1384, 1384. e1.

27. Lao TT, Huengsburg M. Labour and delivery in mothers with asthma. Eur J Obstet Gynecol Reprod Biol. 1990;35(2-3):183-190.

28. Olesen C, Thrane N, Nielsen GL, Sørensen HT, Olsen J; EuroMAP Group. A population-based prescription study of asthma drugs during pregnancy: changing the intensity of asthma therapy and perinatal outcomes. Respiration. 2001;68(3):256-261.

29. Källén B, Rydhstroem H, Aberg A. Asthma during pregnancy a population based study. Eur J Epidemiol. 2000;16(2):167-171.

30. Stenius-Aarniala B, Piirilä P, Teramo K. Asthma and pregnancy: a prospective study of 198 pregnancies. Thorax. 1988;43(1):12-18.

31. Blais L, Kettani FZ, Elftouh N, Forget A. Effect of maternal asthma on the risk of specific congenital malformations: A population-based cohort study. Birth Defects Res A Clin Mol Teratol. 2010;88(4):216-222.

32. Lin S, Munsie JP, Herdt-Losavio ML, et al; National Birth Defects Prevention Study. Maternal asthma medication use and the risk of selected birth defects. Pediatrics. 2012;129(2):e317-e324.

33. Källén B, Otterblad Olausson P. Use of anti-asthmatic drugs during pregnancy. 3. Congenital malformations in the infants. Eur J Clin Pharmacol. 2007;63(4):383-388.

34. Lim AS, Stewart K, Abramson MJ, Ryan K, George J. Asthma during pregnancy: the experiences, concerns and views of pregnant women with asthma. J Asthma. 2012;49(5):474-479.

35. Murphy VE, Gibson PG, Talbot PI, Kessell CG, Clifton VL. Asthma self-management skills and the use of asthma education during pregnancy. Eur Respir J. 2005;26(3):435-441. 
36. Powell H, McCaffery K, Murphy VE, et al. Psychosocial outcomes are related to asthma control and quality of life in pregnant women with asthma. J Asthma. 2011;48(10):1032-1040.

37. Sawicki E, Stewart K, Wong S, Paul E, Leung L, George J. Management of asthma by pregnant women attending an Australian maternity hospital. Aust N Z J Obstet Gynaecol. 2012;52(2):183-188.

38. Lim AS, Stewart K, Abramson MJ, George J. Management of asthma in pregnant women by general practitioners: a cross sectional survey. $B M C$ Fam Pract. 2011;12:121.

39. McCallister JW, Benninger CG, Frey HA, Phillips GS, Mastronarde JG. Pregnancy related treatment disparities of acute asthma exacerbations in the emergency department. Respir Med. 2011;105(10):1434-1440.

40. Schatz M, Dombrowski MP, Wise R, et al; National Institute of Child Health and Human Development Maternal-Fetal Medicine Units Network; National Heart, Lung, and Blood Institute. Spirometry is related to perinatal outcomes in pregnant women with asthma. Am J Obstet Gynecol. 2006;194(1):120-126.
41. Suissa S, Ariel A. US Food and Drug Administration-mandated trials of long-acting $\beta$-agonists safety in asthma: will we know the answer? Chest. 2013;143(5):1208-1213.

42. Greening AP, Ind PW, Northfield M, Shaw G. Added salmeterol versus higher-dose corticosteroid in asthma patients with symptoms on existing inhaled corticosteroid. Allen and Hanburys Limited UK Study Group. Lancet. 1994;344(8917):219-224.

43. Nelson HS, Weiss ST, Bleecker ER, Yancey SW, Dorinsky PM; SMART Study Group. The Salmeterol Multicenter Asthma Research Trial: a comparison of usual pharmacotherapy for asthma or usual pharmacotherapy plus salmeterol. Chest. 2006;129(1):15-26.

\section{Publish your work in this journal}

The Journal of Asthma and Allergy is an international, peer-reviewed open-access journal publishing original research, reports, editorials and commentaries on the following topics: Asthma; Pulmonary physiology; Asthma related clinical health; Clinical immunology and the immunological basis of disease; Pharmacological interventions and

\section{Dovepress}

new therapies. Issues of patient safety and quality of care will also be considered. The manuscript management system is completely online and includes a very quick and fair peer-review system, which is all easy to use. Visit http://www.dovepress.com/testimonials.php to read real quotes from published authors.

Submit your manuscript here: http://www.dovepress.com/journal-of-asthma-and-allergy-journal 